\title{
A Strategic Approach for Regional Fisheries Organization Establishment in Northeast Asia
}

\author{
Yong-Min Shin* \\ Full-time researcher, Institute of Humanities and Social Sciences, Pukyong National University,
}

Busan, 608-737, Korea

\begin{abstract}
This study considers an approach for subregional fisheries organization in Northeast Asia. The fishery resources in the Northeast Asian waters surrounding Korea are among the most productive in the world because of their extremely high biological productivity and the natural features of the sea. However, the fishery resources of the region have long been subject to heavy fishing pressures, and many stocks are now believed to be seriously depleted or even in danger of extinction because of overfishing. To move to a run sustainable fishery in Northeast Asia waters area, cooperative fisheries management between Korea, China and Japan for common resource is probably necessary. Cooperative fisheries management is likely to be more effective in fishery resources management than individual fisheries management by countries. The effects of fisheries management by regional cooperation can be divided into resource management and economical performance. Cooperative fisheries management as RFO will bring satisfactory results. Currently these jurisdictional extensions and resulting disputes over maritime space and resources were thrust upon an already transitional and unstable political environment. However, They have to have a strategic approach for RFO establishment step by step. Cooperative fisheries management using the RFO can mitigate these disputes, and cooperative bilateral fisheries arrangements have been proliferating over the past 10 years and may provide the basis for possible trust-building multilateral agreements.
\end{abstract}

Keywords : Northeast Asia, Fisheries Management, Regional Fisheries Organization, EEZ, UNIA

\section{I . Introduction}

The important role of regional and subregional fisheries organizations in the conservation and management of the high seas fisheries has long been recognised. The provisions of UNCLOS concerning the role of regional and subregional fisheries organizations are reiterated, emphasized and expanded by the UN Agreement on Straddling Fish Stocks and Highly Migratory Fish Stocks. The
게재확정 : 2013년 11월 28일
접수 : 2013년 11월 12일 최종심사 : 2013년 11월 25일
* Corresponding author : 010-9755-6256, sym@korea.com 
core of the UN Agreement is that high seas fisheries must by managed effectively on a regional or subregional basis through existing fisheries organizations or arrangements or by establishing new ones.

Regional and subregional fisheries organizations (RFOs) must first and foremost identify with the region or the subregion they are representing. They must manage and be seen to manage the resources of the region in the interest of the coastal states of the region with legitimate interest in the conservation and management of the resources of that region. To be able to respond quickly and efficiently to the conservation and management needs of a region or a subregion it is imperative that the relationship between the fisheries organizations and their members become more of a partnership bridging the gap between the advisory and decision-making functions. There are more than twenty regional and subregional fishery organizations whose mandates include the conservation and management of high seas fisheries. Some have full regulatory powers while others have an advisory role related to management issues.

There is not, however, any organization for regional fisheries cooperation in Northeast Asia. The reason is various kinds such as political, economical, and historical situations with the exception of fisheries interests. This study outlines a strategic approach for regional fisheries cooperation for the desirable management and conservation of fish stocks in Northeast Asian waters. The model and recommendations will be based on international law, current situation with the regions' fisheries, and the experience of other regions. This paper consists of the necessity, conditions of regional fisheries cooperation, and development of models for cooperative fisheries management in Northeast Asia.

\section{II . Conditions for RFO Establishment in Northeast Asia}

\section{Preconditions for regional fisheries cooper- ation}

The types of international cooperation for fisheries management divide into cases that establish fisheries organization and cases that enforce by international agreements. Especially, the important role of regional and subregional fisheries organizations in the conservation and management of the high seas fisheries has long been recognized.

What are the conditions that make possible the development of durable regional fisheries management measures? This fundamental question has been a continuing concern for theorists and policy-makers, and it is an extraordinarily difficult one to answer, given the sui generis nature of every regional experience and the virtual impossibility of showing direct casual links in the development of such complex systems. The following are some of the elements, which have been raised as potentially determinative:

- pre-existing habits of cooperation and institutional development, which in the same sector or more generally and possibly extending to the presence of relevant functioning institutions;

- national and regional leadership;

- clearly defined benefits to be gained through regional cooperation, which may be based on the presence of significant management challenges with clear regional dimensions;

- the need for capacity-building, whether at the 
national level or through regional sharing of management capabilities;

- the presence of external threats (e.g., distant water fishing nations) which may consolidate the regional position, and which may require a united front for an effective response;

- intra-regional maritime disputes which threaten security generally, and which motivate a regime for conflict avoidance and/or dispute resolution;

- cultural and political homogeneity;

- the existence of significant transnational networks of scientific or other communities which can provide both information on management issues, and the stimulus for action;

- public awareness and concern with a given issue or range of issues; and

- level of economic development and availability of funding sources.

Therefore, regional and subregional fisheries organizations must first identify with the region or the subregion they are representing. They must manage and be seen to manage the resources of the region in the interest of the coastal states of the region and neighbor nations with legitimate interest in the conservation and management of the resources of that region. To be able to respond quickly and efficiently to the conservation and management needs of a region or a subregion it is imperative that the relationship between the fisheries organizations and their members become more of a partnership bridging the gap between the advisory and decision-making functions.

To be effective in the conservation and management of the resources, regional and subregional fisheries organizations must have a clear mandate to discharge their management duties. In addition, they should have mechanisms through which they receive scientific advice related to management issues. Whether such advice is provided by internal sources or external organizations, the organizations' members should conceive them as fair, neutral, and free from national interests, politics and economics. The effectiveness of fisheries management organizations depend on the commitment of their members to implement the regulatory measures adopted by them. Member states of a fisheries management organization should promptly and give effect to the management measures adopted by that organization immediately.

A major problem faced by many fisheries management organizations is the undermining of their regulatory and other conservation measures by countries not parties to the conventions or agreements who allow their flag vessels to be used for fishing on the high seas. The Provisions of the UN Agreement on Straddling Fish Stocks and Highly Migratory Fish Stocks and the Agreement to Promote Compliance with International Conservation and Management Measures by Fishing Vessels on the High Seas was designed to tackle this problem. The FAO Code of Conduct on Responsible Fisheries also addresses this problem.

Regional and subregional fisheries organizations or arrangements must have a mechanism through which their conservation and management measures are enforced. Thus, control, surveillance and enforcement must be part of the activities of any fisheries organization whose mandate includes the conservation and management of fisheries resources. A regional or subregional fisheries organization needs adequate funding to be able to function properly. To have a mandate for conservation and management without the financial means to execute them will not improve the 
effectiveness of the fisheries organizations. Member states of a regional or subregional fisheries organization or arrangement should agree among themselves as to how the financial needs of their organization should be secured (FAO, 1996).

Cooperation between fisheries organizations operates in the same area or overlapping areas as well as those dealing with highly migratory and straddling fish stocks, is essential. Greater efficiency could be achieved if the regional bodies worked together more closely. The management issues related to straddling stocks depend on their biological characteristics and, in particular, on the degree of mixing between the EEZ and high seas compartments of stocks. In many instances where mixing is considerable because of random dispersion, ontogenic or seasonal migrations, the stock should be managed as one single unit and management measures must be harmonised over the entire range of distribution of the stock. In this context, cooperation is seen as an essential part of conservation and management functions of fisheries organizations.

\section{Conditions in Northeast Asia}

The past few decades have witnessed the emergence of a vast array of regional arrangements and institutions dealing with all aspects of ocean and fisheries management. The level of cooperation ranges from minimal dispute avoidance to relatively comprehensive fisheries management at regional level. As concrete case studies, reasonably successful and comprehensive regional management cooperation have been created for the Mediterranean, the Caribbean, the Baltic, and the North Sea as well as the South Pacific Ocean, and attempts at regional cooperation building are ongoing in Southeast Asia, the South China Sea and the Indian Ocean. Although there are broad similarities between many of these semi-enclosed seas and those of Northeast Asia, no regional fisheries cooperation has yet been initiated in Northeast Asia (Valencia, 2001).

This variety of experiences raises several questions. What factors are conductive to fisheries cooperation initiation, expansion and positive evolution, and which constrain fisheries cooperation formation and growth? The preceding section, some of the general issues derived from experience have been outlined. Why has fisheries cooperation building been successful (to a limited extent) in Europe and largely unsuccessful in Northeast Asia? And which, if any, lessons learned in other contexts are applicable in the region?

This section describes and explains existing or incipient regional fisheries cooperation in an unusually broad comparative context, and extracts lessons learned that may be applicable elsewhere, including Northeast Asia. From these and other examples, it is possible to retire our discussion of the general factors that favor or retard multilateral maritime regime formation. These factors may or may not be applicable in Northeast Asia.

The difficulties experienced in promoting the need for fisheries cooperation in Northeast Asia may be due to the special, if not unique, political characteristics of the region. Much might be made, for example, of the region's lack of any history or tradition of political cooperation. The Chinese, Japanese, Korean and Russian peoples who dominate the region have always been uneasy neighbors at best, and often bitter enemies. Even though there is less hostility now in the relationships among China, Taiwan, Japan Korea, North Korea and Russia?less perhaps than at any point since the mid- $19^{\text {th }}$ century?the cultivation of 
truly congenial relations at the inter-governmental level continues to tax the diplomatic skills of their most enlightened officials and politicians. Accordingly, the political milieu of Northeast Asia seems the least favorably inclined of all regions to support a formal initiative for inter-governmental regime building. Almost any bold proposal by one of these countries would seem bound to provoke suspicions on the part of at least two of the others (Johnston, 2001).

There is also a marked degree of distinctiveness in the marine geography of Northeast Asia. Whereas most other marine regions consist of countries that look out at a single sea or ocean that is perceived as a shared, and potentially unifying, environment?as an extension of their land-based economies?the countries of Northeast Asia look out either at the North Pacific, which is too vast to be perceived as their "shared dominion", or at a number of discrete seas (Yellow, East China, East and Okhotsk) in each of which strong "patrimonial" sentiment on the part of at least one coastal state tends to undermine the concept of shared authority. The geography of Northeast Asia seems unfriendly to the ideal of regional cooperation regarding the seas.

Moreover, half of these countries are too affluent for Northeast Asia to be eligible for UN designation as a developing maritime regime. Only China and North Korea clearly meet the traditional UN criteria for such treatment. Of the various seas of Northeast Asia, perhaps only the Yellow Sea comes close to qualifying as a developing marine area, albeit with Korea as one of the three coastal states. This anomaly, which prevented the inclusion of the seas of Northeast Asia in the 'East Asian Seas' designed by United Nations Environment Program, still makes it necessary for China to be treated as part of Southeast Asia for this purpose.

It must also be said that the cause of regional cooperation in Northeast Asia is complicated by having at its center a country with huge potential, limited capacity, an ancient tradition of cultural domination, and a continuing foreign policy that seems to reflect a basic reluctance to be part of a multilateral regional regime on an equal footing with lesser powers.

With good reason, Chinese rhetoric for over 50 years has been obsessed with the threat of US hegemony in the North Pacific, but China's own posture in recent years has been widely perceived as equally hegemonic. Perhaps more than anything else, China's desire for leadership status in Northeast Asia discourages bold efforts by its neighbors to embark on costly regime-building initiatives. Very clearly, the Chinese preference in the region is for bilateral arrangements within their control.

\section{Comparisons between other areas and Northeast Asia}

Although Western Europe and Northeast Asia have obvious fundamental differences, on some criteria they are sufficiently similar as regions to be compared. Indeed, there are broad geographic, oceanographic, economic and political similarities between the semi-enclosed seas of Western Europe and Northeast Asia. For example, the East Sea is physically similar to the Mediterranean in its great depths and narrow connections to its main oceanic water body. The Yellow Sea is similar to the Baltic in its shallowness, heavy pollution, low flushing rates, overfishing of transnational stocks and conflicting multiple uses. Moreover, the East China Sea and the North Sea are similar in that they are underlain primarily by continental shelf, have high 
hydrocarbon potential, and have wide connections to the main ocean. Ecologically, the East Sea is similar to the Baltic, the Yellow Sea to the North Sea, and the East China Sea, at least in its southern part, to the Mediterranean (Valencia, 2001).

More important in terms of maritime regime initiation are the similarities in economic and political diversity of the nations bordering and enclosing these seas. The Baltic and the Mediterranean are bordered by both developed and developing countries. For the Baltic, this juxtaposes Denmark, Germany, Sweden, Poland and Russia. For the Mediterranean, France, Italy and Spain are contrasted with Algeria, Libya, Morocco and Tunisia. This economic diversity is also characteristic of the East Sea rim (Korea and Japan vs. Russia); the Yellow Sea rim (Korea vs. China and North Korea); and the East China Sea rim (Japan, Korea and Taiwan vs. China).

Indeed, the differences between the two regions are not as obvious as they may superficially seem. For those who would point to a united and politically integrated Europe as the fundamental reason for the relative success of maritime regimes there. One might suggest that the bitter sovereignty disputes over islands such as Dok-do and Senkakus (Diaoyutai) and their attendant maritime space are the constraint to maritime regime initiation in Northeast Asia. However, Greece and Turkey were able to join and cooperate in the Mediterranean regime despite their sometimes-violent dispute over islands in the Aegean. Moreover, in 1973-1976 prior to the initiation of the North Sea regime, the United Kingdom and Iceland engaged in the infamous, "Cod Wars," which involved vessel collisions and shooting incidents.

Discussion of the EU's Common Fisheries Policy (CFP) is the representative example. These are many questions about the EU's CFP such as its performance, systems, problems, and the applicability in Northeast Asia. The CFP in European Union (EU) was formally created in 1983, but its origins date back to the early 1970s, when fisheries were originally part of the Common Agricultural Policy. Ministers' main concern in those early days was to avoid conflict between nations, at a time when many countries around the world were extending their territorial waters, until they finally created EEZs extending 200 nautical miles from their baseline. Europe's fisheries were already highly 'international', with many fleets used to fishing a long way from home. To avoid the enormous disruption which the new EEZ regime could have caused, the emerging European institutions brokered a deal under which Member States agreed to grant free mutual access to each other waters, so that each nation's traditional fishing grounds and practices could be preserved (European Commission, 2009).

The Commission has started a review of the common fisheries policy to make it more efficient in ensuring the economic viability of the European fleets, conserving fish stocks, integrating with the maritime policy and providing good quality food to consumers. One of the oldest elements of the CFP is the principle of 'relative stability'. The question of how to divide fishing opportunities up into national quotas was sparked by the setting of the first catch limits affecting EU fleets. Relative stability was first applied in practice with the adoption of the CFP in 1983. Under this system, Total Allowable Catches (TACs) for each fish stock are shared out between the Member States of the EU according to a fixed allocation key based on their historic catches. The purpose of relative stability is, as the term suggests, to prevent 
repeated arguments over how quotas should be allocated, and to provide fishers with an environment which is stable relative to the overall state of the stock in question. Like any attempt to manage a complex, multi-factorial situation through a formula which is relatively simple and straightforward to understand and to apply, the principle of relative stability has disadvantages as well as advantages (Eurepean Commission, 2009).

The European Commission launched a Green Paper (European Commission, 2001) on the reform of the CFP after 2002, outlining a series of options for the strengthening and improvement of the CFP. In many areas of its application, it is considered to have been a failure. The Green Paper gives an account of the current poor fisheries situation in the European Community. It is well known that the state of fish stocks is far from satisfactory and that some of the most important European fish stocks, such as North Sea cod and northern hake, are on the verge of collapse or are outside safe biological limits. The Green Paper also acknowledges that the current bleak situation results from excessive Community fishing capacity and effort and that conservation measures have not been effective enough to protect fish stocks and marine ecosystems. The fisheries sector is characterized by economic fragility resulting from over-investment, high rising costs and a decreasing resource base. As profits decline, fishermen tend to fish harder which then leads to further damage to fish stocks and marine ecosystems and undermines the economic situation of the industry as a whole.

Theory based on the European experience is also not very helpful in other respects. Europe has the EU. The EU has a CFP in order to manage fisheries for the benefit of both fishing communities and consumers. There seems to be a general premise in the literature that lessons learned in one region are transferable to another. For example, Haas has analyzed the prospects for effective fisheries management in Northeast Asia and has concluded that the main reasons for the failure to initiate maritime regimes are weak international institutions; weak organization of knowledge; the lack of willing regional leadership; and most important, the lack of an epistemic community to pressure governments (Haas, 2000; Valencia, 2000).

While one might debate the effectiveness of transnational linkages in Northeast Asia, they do exist. Indeed, fisheries concern in the region is strong and growing, and there is relatively high capacity for formulating fisheries policy. Yet, fisheries cooperation has not been initiated in the region. We thus return to our original questions: are all lessons learned in the European context applicable to Northeast Asia, and if not, which are, and what are the reasons that maritime regime initiation, implementation and evolution have been unsuccessful there (Sand, 1992)? To answer the first question we must undertake a re-analysis of the factors favoring success in Europe.

\section{Obstacles to be overcome and difficult points}

In marine ecosystem and the United Nations Convention on the Law of the Sea (UNCLOS) respect, Korean peninsula's waters, the East Sea, the Yellow Sea and the East China Sea, have good situations for establishment of the regional fisheries organization. The RFO needs cooperation between country in the area and data exchange, and high interest for resource conservation to succeed. However, these cooperation and preparation are lacking between Korea, China and Japan.

Since concluding a treaty of amity between 
Korea and China in 1992, political antagonistic relationships in Northeast Asia, except the North Korea, was mitigated rapidly and intergovernmental meeting, NGOs conversation, and exchange of data in the region has been lively. Therefore, a RFO establishment possibility in the region is high.

Positive perceptions of cooperation are also necessary for successful regional efforts. Clearly, public and private institutions must establish regional links, and there must be a political commitment to the regional concepts, and a regional goal. The Northeast Asian countries are clearly divided on this issue. In order to maintain momentum, expectations of progress must also be reasonable but they must be satisfied. Conversely, if no progress is made within a reasonable time, the movement toward cooperation is weakened or its objectives are altered. Several bilateral fisheries agreements were only initiated of maritime regime of the regional EEZ. Therefore, without the full participation of Korea, China and Japan, an effective fisheries management is impossible. However, China is preoccupied with internal matters, and has been concerned to the South China Sea. Moreover, even there it has been most reluctant to cooperate. Indeed, China is generally opposed to any an all-multilateral cooperation that could constrain its options, preferring bilateral cooperation which it can dominate and control. Moreover, with tension over Taiwan ratcheting up, China is reluctant to enter any discussions that include it indirectly or otherwise.

As for Japan, it simply lacks the political will and credibility to lead the formation of a multilateral regime in Northeast Asia. Korea could assume a key role by enabling the major powers to avoid appearing too dominant or assertive.
However, it may not be able to lead, and if it did lead, China and Japan might not follow.

Finally, the strong resurgence of the traditional concept of sovereignty prevails in Northeast Asia ? with clear and manifest reasons. Here the uncertainty and weakness of states are obstacles to cooperation. Identity formation and exclusion are maximized at the state level preventing a rival process of identity to evolve at the regional level. This concept must become more flexible before a formal multilateral fisheries agreement can form.

Fisheries management system formation in Northeast Asia-at least a formal system?is retarded by several factors:

- China's opposition to potentially constraining multilateral efforts. Its opposition to such initiatives unless it leads, and its relative disinterest in Northeast Asian fisheries affairs;

- Japan's lack of political will and unwillingness to follow the lead of others such as Korea;

- the resources of traditional sovereignty concerns which undermine efforts at regional identity formation; and

- deeply-rooted differences in priorities regarding fishery resource protections.

Because of fishery and non-fishery issues, cooperative fisheries management in Northeast Asia falls into a difficult situations. In fisheries issues, fisheries structure, management systems and technologies are a great difference among Korea, Japan and China. As a non-fisheries issue, they have a bad national sentiment from historic experience, and there is territorial dispute in sea. In addition, in an economic point of view, there is a great difference in the region. 


\section{An approach to RFO establishment in NE Asia}

\section{The course of regional fisheries cooperation}

Regional cooperation for fisheries management is by no means limited to ensuring the compatibility of existing measures, but also includes the establishment of new measures, and the mechanisms by which they are agreed. For both straddling stocks and highly migratory stocks, coastal states and states fishing on the high seas are obliged to cooperate to ensure the effective management and conservation of the stocks in the Straddling Fish Stocks and High Migratory Fish Stocks Agreement (Article 8(1), UNIA ${ }^{1)}$ ). Where the stocks are threatened, or a new fishery is being developed, this cooperation is translated to an obligation to enter into consultations in good faith and immediately (Article 8(2), UNIA).

The principle mechanism to provide for cooperation is envisaged to be a regional fisheries management organization, membership of which must be open to all states with a "real interest in the fisheries concerned" (Article 8(3), UNIA). Where no organization exists, states are obliged to create one, for either straddling or highly migratory stocks, or else initiate an alternative arrangement to fulfill the same function (Article 8(5), UNIA). The incentive to compel participation of states in regional fisheries organizations is a denial of access to the high seas fisheries the organizaion has responsibility for (Article 8(4), UNIA).

Clearly, under the Agreement, the role of the regional fisheries organization is significant, and it reinforces this role with additional provisions.
Existing organizations are to be strengthened, to improve their effectiveness in tackling conservation and management of straddling and high migratory stocks (Article 13, UNIA). States are obliged, through the medium of the regional organization, to cooperate on a plethora of initiatives designed to further conservation and effective management of fish stocks. These include:

- conservation and management measures;

- participatory rights;

- adoption and application of generally recommended international standards for responsible fishing;

- collection and evaluation of scientific advice;

- standard setting for data collection, verification and exchange;

- compilation and dissemination of data;

- promotion and conduct of stock assessments;

- establishment of appropriate cooperative mechanisms for effective monitoring, surveillance and enforcement;

- means for participation of new members;

- decision-making designed to facilitate the adoption of conservation and management measures in a timely and effective manner;

- promotion of peaceful dispute settlement;

- cooperation of national agencies to implement the organization's decisions; and

- due publicity to conservation and management measures.

In addition, in recognition of the importance of data collection and scientific research to the viability of a successful management system utilizing a precautionary approach, the Agreement sets standard requirements for data collection and

1) 1995 United Nations Agreement for the Implementation of the Provisions of the UN Convention relating to the Conservation and Management of Straddling Stocks and Highly Migratory Fish Stocks 
dissemination (Article 14, UNIA).

There are several models of international cooperation in fisheries management. The first model is cooperation by waters. A weakness of this cooperation is the lack of financial resources. However, this is also an advantage in that these countries can take immediate action once such financial resources on available. The second model is cooperation by fishery species. The strength of such cooperation is the more readily available financial resources for cooperative activities. As long as the relevant countries reach a consensus on concerted action, practical results will be achieved. The third model is cooperation by fishing types. Cooperation of this kind is characterised by differences in capacity and financial resources and by the different bases for cooperation.

\section{Establishment of a regional fisheries organization}

Geographically, RFOs are either regional or subregional. More importantly, either they may cover areas of high seas, the EEZs of participating states, or a geographical area comprised of both high seas areas and EEZs. In the majority of cases, the geographical scopes are defined as geographic areas or migratory routes comprising of both EEZs and high seas. RFOs mandates may cover either all or selected fish stocks within their geographic areas of competence. Such stock coverage is subject to the distinct characteristics of the stocks in the regions (Sydnes, 2001).

RFOs are generally established by states as political solutions to collective action problems. States are seeking to achieve specific objectives by cooperation. A first step in categorizing RFOs is therefore to identify the objectives they were established to promote. These objectives are commonly made explicit by the RFOs constitutive agreements. It must be recognised that the objectives of an RFO may change over time either through amendments to the constitutive document or because objectives are not acted upon.

Three main categories of RFOs exist: scientific research organizations, regional coordination and development organizations, and regional fisheries management organizations. These categories can be illustrated by some examples. The International Council for the Exploration of the Sea (ICES) was established in 1902 as a scientific research organization with the mandate to promote and encourage marine research, draw up programs and organize research, and disseminate the results of its activities. The Forum Fisheries Agency (FFA), on the other hand, is a regional coordination and development organization mandated to promote intraregional cooperation and coordination regarding the harmonisation of fisheries management policies, relations to distant water fishing nations (DWFNs), surveillance and enforcement, fish processing, marketing, and access to each Other's EEZs. Finally, the NorthEast Atlantic Fisheries Commission (NEAFC) is a regional fisheries management organization as reflected in its Convention: The Commission shall perform its functions in the interests of the conservation and optimum utilization of the fishery resources of the Convention Area.

Having different objectives, the three categories of RFOs achieve their objectives by performing different tasks and have different interest structures underlying the cooperation between the member countries. Scientific research organizations generally facilitate cooperation by conducting and coordinating marine research and by providing member countries or other RFOs with scientific 
material and advice. Their functions are mainly performed through programs or procedures whereby members coordinate efforts to generate common, scientific knowledge. Such RFOs are established, generally speaking, as exploratory ventures with little substantive conflict of interests among the state parties.

Regional coordination and development organizations primarily coordinate the efforts of member countries related to the development of the regional fishing industry and the harmonization of national fisheries policies. Such organizations commonly perform their tasks by establishing regulations coordinating joint efforts regarding harmonization of national policies and through programmatic tasks related to the development of the fishing sector. Such RFOs are established based on the member countries common interests. Regional fisheries management organizations are established to manage fisheries resources in the traditional sense. Their functions may include collecting and assessing scientific information, setting regulatory measures, including the determination of quotas, and the adoption of enforcement mechanisms.

\section{A framework to be considered for establishing an RFO}

As Sandler(1997) pointed out, an initial international regime should not undermine the autonomy of the participating countries too much. If initial agreements are too complex and require participants to surrender a great deal of sovereignty, participants would not participate actively in the agreement and negotiations could take a long time or fail to reach a conclusion.

In the region, in practice, it may take time to establish an RFO and operate it effectively, taking into account historic and ongoing fishery dispute, distorted fishery relations based on bilateral agreements, and different fishery interests among coastal states, and complicated political situations. These factors may undermine the establishment of an RFO in the region. As well, the negotiations for it could drag on for a long time and compromise will be difficult to reach.

In order to solve these problems, to make it easy to establish an RFO, and to encourage the countries concerned to participate in it actively, the first stage of fishery cooperation in the region might be expected to be regular meetings of an expert group developing from loosely structured consultative bodies, rather than the direct establishment of an RFO (Kang, 2003).

For example, in an initial stage, establishing a strong RFO in the region could discourage the active participation of countries that are intensifying their fishing activities, such as China. A loosely structured body may encourage coastal states in the region to participate actively in international cooperation to improve fishery resources, and provide a basis for establishing an RFO. Therefore, it is more desirable for initial cooperation to start with creating a formal expert group with representatives from each coastal state concerned.

The next step would be to design and establish an RFO to manage and conserve fisheries resources in the region. If a study by the expert group supports action to strengthen regional cooperation for the conservation of fish stocks, the initial meetings by the expert group could lead the governments of the region to proceed to the negotiations of a more formal and concrete cooperative arrangement. This could later be embodied in an RFO agreement so that the regime 
can enforce strict management measures to ensure the conservation and sustainability of fish stocks in the region.

Therefore, in order to establish an RFO in the region, two steps could be taking: one is to create a formal meeting of experts from the fishing countries concerned; another is to establish an RFO based on the recommendations or the results of a study by the experts group. In fact, without reliable scientific data supported by a meeting of experts, it is impossible to make meaningful progress in the management and conservation of fishery resources on a long-term basis and reach an arrangement that is acceptable to all parties.

In this section, therefore, these two steps for establishing an RFO are discussed. In particular, based on Sandler's design principles for establishing an international regime, the major elements in establishing an RFO are considered. These recommendations take into account international legal provisions for dealing with the conservation and management of straddling fish stocks, in particular UNIA, as well as the experience gained from other existing RFOs.

\section{IV . Conclusion}

In recent years, there has been a progressive globalisation of the issues considered relevant to the regulation of marine living resources utilization. This has led to a divergence between the institutional framework set up under UNCLOS for this purpose and the nature of the fisheries regulation problem. This divergence between "nominal" and "real" boundaries of states rights over marine resources under the current legal regime implies taking new forms of external effects into account in the identification of socially optimal harvesting patterns and of possible ways to achieve them. Although extensions of the bioeconomic model provide useful tools for the analysis of this problem, they also lead to underline the uncertainty that prevails concerning the nature and extent of these external effects.

In the absence of a supra-national authority, the result in practice appears to be an increased instability of international agreements based on the definition of optimum patterns of resource utilization. Such optimum schedules are bound to evolve according to the information available to each party, their expectations about future "state of nature", and their perceptions of what an equitable solution should be. Taking this instability into account leads to consider the procedures guiding the decision-making process as the first object of bargaining and agreement. This is apparent in the growing interest in the type of organizational designs required for the management of marine living resources.

Northeast Asian countries have many problems in fisheries management. The Northeast Asian waters are semi-enclosed seas, and almost all fish stocks migrate beyond one country's jurisdiction and are shared among the coastal countries in the region. These biological and geographical features have accelerated overexploitation of fish stocks in the region because of competitive fishing. As a result, most commercial fish stocks are fully exploited or overexploited, and some are depleted. Therefore, urgent action at the international level is required to rebuild fishery resources and to maintain harvests at a sustainable level.

Therefore, fisheries cooperation between Korea, Japan and China seems sensible. To achieve this objective, the most effective method is establishment of a subregional fisheries organization. From this 
viewpoint, we suggested a model and plans of regional fisheries organization in Northeast Asia. An RFO has substantial advantages from the perspective of conservation. The RFO would assume responsibility for the effective management of marine fisheries in a geographically delimited area. It would be have exclusive rights over a geographic area that encompasses an appropriate ecological unit, taking into account the range and degree of mixing of fish stocks, geographical characteristics, and monitoring and enforcement issues. In order that the RFO be successful, its institutional structure should be well designed so that it can implement its mandate fully and achieve its objectives for the conservation and management of fishery resources.

\section{REFERENCES}

European Commission (2006), “About the Common Fisheries Policy," Available online at $<$ http://ec.europa.eu/fisheries/cfp/management_ resources_en.htm>.

European Commission (2009), “The Common Fisheries Policy-A User's Guide," Luxembourg: Office for Official Publications of the European Communities.

European Economic and Social Committee (2002), The Common Fisheries Policy, The Road Travelled and the Challenges Ahead, Publications Office, EU, $1-$ 48.

FAO (1996), The Role of FAO Regional Fishery Bodies in the Conservation and Management of Fisheries, by S.H. Marashi, International Institutions and Liaison Service FAO Fisheries Department, Rome, Italy.

FAO (2001), Fisheries Enforcement Related Legal add Institutional Issues National, Subregional or Regional Perspectives, FAO Legislative Study 716 Erik Franckx for the Development Law Service, FAO Legal Office, Rome, Italy.
Haas, P. M. (2000), "Prospects for Effective Maritime Governance in the NW Pacific Region," Marine Policy, 24(4), $341-348$.

Johnston, D. M. (2001), "Southeast Asia: Lessons Learned," Maritime Regime Building: Lessons learned and Their Relevance for Northeast Asia, edited by M.J. Valencia, Kluwer Law International, $73-86$.

Kang, J. S. (2003), “The United Nation Convention on the Law of the Sea and Fishery Relations between Korea, Japan and China,” Marine Policy, 27(4), $111-124$.

Sandler, T. (1997), Global Challenges - An Approach to Environment, Political, and Economic Problems, Cambridge University Press, Cambridge, UK.

Saunders, P. (2001), "Marine Regional Cooperation Theory and Principles," Maritime Regime Building, Lessons Leaned and Their Relevance for Northeast Asia, edited by Mark J. Valencia, Kluwer Law International, Netherlands, $1-16$.

Shin, Y. M. (2011), Institutional Options for Cooperative Fisheries Management in Northeast Asia : an Analysis and Evaluation, University of Bath.

Sydnes, A. K. (2001), "Establishing a Regional Fisheries Management Organization for the Western and Central Pacific Tuna Fisheries," Ocean \& Coastal Management, 44, 787-811.

Sydnes, A. K. (2001), "Regional Fishery Organizations: How and Why Organizational Diversity Matters," Ocean Development \& International Law, 32, 349372.

Valencia, M. J. (1987), International Conference on the Yellow Sea, A Summary Report of the Conference held at the East - West Centre, 23-37 June 1987, Occasional Paper, 3, 24-25.

Valencia, M. J. (1988), The Sea of Japan: Transnational Ocean Resource Management Issues and Options for Cooperation, East-west Environment and Policy Institute, USA.

Valencia, M. J. (1996), A Maritime Regime for NorthEast Asia, Oxford University Press, Hong Kong. 


\section{Yong-Min Shin}

Valencia, M. J. (2000), "Regional Maritime Regime Building: Prospects in Northeast and Southeast Asia," Ocean Development \& International Law, $31,223-247$.
Valencia, M. J. (2001), Maritime Regime Building, Lessons Leaned and Their Relevance for Northeast Asia, Kluwer Law International, Netherlands, $17-$ 26. 